\title{
FIM DA PROTEÇÃO DO COMÉRCIO BILATERAL BRASILEIRO NO SETOR TÊXTIL E DE CONFECÇÕES
}

Thiago Fellipe Lima Silva Pereira ${ }^{1}$ Monaliza de Oliveira Ferreira ${ }^{2}$

Resumo: Este artigo teve como objetivo analisar os efeitos do fim da proteção comercial internacional do setor (ATV) sobre o comércio bilateral do Brasil com seus parceiros importadores no período de 1997-2017. Para este fim foi utilizado o modelo gravitacional. Este estudo mostra que, mesmo com a falta de competitividade do Brasil no setor têxtil e de confecções, o fim do acordo sobre têxteis e vestuário (ATV) impactou positivamente o fluxo de comércio do país com seus parceiros comerciais. Conclui-se que o conhecimento das vantagens de um ambiente de comércio amplamente competitivo é vital para se avaliar políticas para melhor inserção do setor têxtil e de confecções no comércio internacional.

Palavras-chave: Mundo globalizado. Comércio internacional. Competitividade do Brasil. Setor têxtil e de confecção. Modelo gravitacional.

\section{END OF PROTECTION OF BRAZILIAN BILATERAL TRADE IN THE TEXTILE AND CLOTHING SECTOR}

Abstract: This research aimed to analyze the effects of the end of the agreement on Textiles and Clothing (ATC) on the bilateral trade of Brazil with its importing partners in the period of 1997-2017. For this purpose, the gravitational model was used. the end of the agreement on Textiles and Clothing (ATC) positively impacted the country's trade flow with its trading partners Concluding that the knowledge of the advantages of a widely competitive trade environment is vital to evaluate policies for better insertion of the textile and apparel sector in international trade.

Keywords: Globalized world. International trade. Competitiveness of Brazil. Textiles and apparel industry. Gravitational model.

\section{FIN DE LA PROTECCIÓN DEL COMERCIO BILATERAL BRASILEÑO EN EL SECTOR TEXTIL Y ROPA}

Resumen: Este artículo tuvo como objetivo analizar los efectos del fin de la protección del comercio internacional (ATV) del sector en el comercio bilateral de Brasil con sus socios importadores en el período 1997-2017. Para este propósito, se utilizó el modelo gravitacional. Este estudio muestra que, a pesar de la falta de competitividad de Brasil en el sector textil y de la confección, el final del acuerdo sobre textiles y confección (ATV) impactó positivamente el flujo comercial del país con sus socios comerciales. Se concluye que el conocimiento de las ventajas de un entorno comercial ampliamente competitivo es vital para evaluar las políticas para una mejor inserción del sector textil y de la confección en el comercio internacional.

Palabras clave: Mundo globalizado. Comercio internacional. Competitividad de Brasil. Industria textil y del vestido. Modelo gravitacional.

\footnotetext{
${ }_{1}$ Universidade Federal de Pernambuco, Estudante do Programa de Pós-Graduação em EconomiaPPGECON, Caruaru, Brasil, thiago.fellipe.lima.sp@gmail.com, https://orcid.org/0000-0001-57845790.

2 Universidade Federal de Pernambuco, Docente do Programa de Pós-Graduação em EconomiaPPGECON, Caruaru, Brasil, monaliza.ferreira@ufpe.br, https://orcid.org/0000-0003-2748-8096.
} 


\section{Introdução}

A cadeia produtiva têxtil tem se transformado continuamente em razão das mudanças tecnológicas que permitiram expressivos ganhos de produtividade. A crescente importância do comércio intrablocos a partir da década de 1980, em conjunto com a aceleração do processo de integração dos mercados mundiais, acabou por provocar a migração de parcela significativa da produção da indústria têxtil e de confecções dos Estados Unidos e da União Europeia, tradicionais produtores têxteis, para países com mão de obra mais barata ao redor do mundo, promovida pela baixa especialização necessária do fator trabalho e pelos mínimos requerimentos de infraestrutura de base suficientes à instalação das fábricas, mas que desenvolveram grande poder competitivo nesses setores como China, Índia, Paquistão, Indonésia e Coréia do Sul (GORINI, 2000; BEZERRA, 2014).

Como chamam a atenção Feistel e Hidalgo (2012), foi implementada uma política de liberalização comercial massiva com o intuito de tornar a economia mais competitiva e atender às expectativas da OMC, diante de um mundo crescentemente globalizado e especializado. Já Costa, Conte e Conte (2013) ressaltam que antes de 1990 as empresas tinham sua estratégia de produção voltada para o mercado interno, tendo que se deparar com a competição a nível global, o que requereu a modernização de suas instalações e necessidade de qualificação dos trabalhadores para se manterem competitivas nesse novo cenário.

O setor têxtil e de confecções teve que passar por essas modificações na década de 1990, mas foi o fim dos acordos de proteção comercial que impactou diretamente essa indústria. O Acordo Multifibras (AMF) - 1974 a 1994 - estabelecia quotas sobre as exportações de países em desenvolvimento para países desenvolvidos e o Acordo sobre Têxteis e Vestuário (ATV) - 1995 a 2004 eliminaria gradualmente o sistema de quotas impostas aos países em desenvolvimento, com o intuito de integrar o comércio de artigos do setor têxtil e de confecção às normas da OMC (COSTA; CONTE; CONTE, 2013).

Com a recessão econômica iniciada em 2008 e a crise mundial desencadeada houve queda nas importações de vestuários dos tradicionais compradores mundiais, gerando um alargamento no excedente produtivo na Ásia, sendo os mercados emergentes que absorveram essa oferta, causando particularmente no Brasil um surto de importação (BEZERRA, 2014). 
A indústria de confecção de vestuário brasileira tem sido afetada, tal qual toda a indústria manufatureira nacional, por problemas estruturais e conjunturais da economia brasileira, entre os quais se destacam o longo período de valorização da moeda nacional, os custos elevados de energia, o estado precário de portos e rodovias, que acarreta ineficiências e altos custos e a burocracia complicada que tem que ser enfrentada pelas empresas, ou seja, o Custo Brasil (ARAUJO et al, 2019).

O objetivo deste trabalho consiste em analisar os efeitos do fim da proteção comercial internacional do setor têxtil e de confecções sobre o comércio bilateral do Brasil com seus parceiros importadores no período entre 1997 e 2017.

O trabalho está estruturado em cinco seções, incluindo esta Introdução. A segunda seção descreve informações sobre o Comércio Internacional. Na sequência apresenta-se o Referencial Teórico, Estratégia Empírica; Resultados e Discussão. Por fim, são expostas as Considerações Finais.

\section{Comércio Internacional do setor têxtil e de confecções do Brasil}

O comércio internacional da indústria têxtil e de confecções tem crescido constantemente, revelando as possibilidades de aumento na participação desse setor na parcela comercializada no mercado internacional. O comércio mundial de fibras têxteis - naturais e químicas (sintéticas/ artificiais) - cresceu 27,7\% entre 2006 e 2015, passando de US $\$ 256,0$ para US $\$ 327,0$ bilhões (MENDES JÚNIOR, 2017).

Conforme a Tabela 1, o saldo comercial do Brasil no comércio internacional de produtos têxteis e de confecção no período analisado apenas apresentou superávits entre 2001 e 2005, a partir de 2006 tem apresentando déficits comerciais recorrentes.

A diminuição das exportações brasileiras de produtos têxteis e de confecções, frente ao aumento de suas importações, revela perda de competitividade diante dos produtores externos, motivada, em parte, pela apreciação da moeda brasileira; por problemas estruturais (como questões logísticas) na indústria têxtil nacional e regional, e custos elevados de tributação, que dificultam os produtores do país concorrerem de forma competitiva nos mercados internacional e doméstico (MENDES JÚNIOR, 2017).

A intervenção do banco central nos mercados de câmbio pode, sob algumas condições, estimular exportações e retardar importações. É de conhecimento geral que esta prática tem sido utilizada pela China para atrair ganhos comerciais 
(STAIGER; SYKES, 2008). Outras medidas consideradas pela China referem-se às restrições à exportação em uma variedade de minerais e outras matérias-primas, que incluem cotas de exportação, direitos de exportação, licenças de exportação e outras políticas protecionistas. Enfim, muitas destas práticas comerciais chinesas têm sido questionadas junto a OMC. E mesmo com as parcerias comerciais BrasilChina, a nação brasileira se consitui como um dos principais países no ranking de usuários da política antidumping contra a economia chinesa (WU, 2016). Por fim, também cabe considerar que a China utiliza mão de obra muito barata, comparandose a qualquer economia no mundo, o que traz relações comerciais desvatajosas para estes países em que há maior rigor nas leis trabalhistas (OGASAVARA; MASEIRO, 2013.)

Voltando ao Brasil, com exceção dos setores de alimentos, bebidas e fumo e refino em petróleo, as tarifas aduaneiras aplicadas são bastante elevadas, infligindo implicações negativas sobre a produtividade e competitividade internacional (KUME, 2018). Levando em consideração que qualquer mudança sobre tarifas aduaneiras não acarreta impactos apenas sobre a produtividade, mas gera efeitos sobre o dinamismo tecnológico dos setores e sobre o mercado de trabalho, cabe maior reflexão sobre os valores dessas tarifas e seus efeitos sobre 0 volume comercializado (MIRANDA; CASTILHO, 2018).

Conforme Miranda (2018), dentre as alterações feitas nas tarifas aduaneiras ${ }^{3}$ desde a criação da tarifa externa comum (TEC), uma das mais significativas ocorreu após 2005, quando um dos complexos com níveis já elevados de proteção, o de têxteis e de calçados, obteve a alíquota de $35 \%$, tendo apresentado em 2008 a tarifa média de vestuário em $33 \%$ e a de têxteis em $23 \%$. Ainda segundo esse autor, mesmo essa alíquota tendo sido colocada a pedido do Brasil, para a proteção da produção nacional diante do aumento da demanda nacional e da decorrente concorrência asiática, esse alto nível de proteção estaria aumentando os custos de produção nacionais e assim comprometendo seu grau de competitividade.

A grande incidência de produtos importados indica que o Brasil está deficiente em competitividade e alguns entraves podem ser listados, tais como a alta carga tributária, principalmente para o setor têxtil e de confecções (a maior entre os setores da Indústria de Transformação), a deficiência na defesa comercial nacional, alto custo de infraestrutura, entre outros (DANTAS; GALEANO, 2015).

3 Tarifa Aduaneira é a forma mais simples de política de comércio, sendo um imposto cobrado quando uma mercadoria adentrar pelas fronteiras nacionais. $E$ tendo por efeito encarecer o custo de envio de uma mercadoria de um país para outro (KRUGMAN; OBSTFELD, 2015). 
Por outro lado, o aumento das exportações chinesas também é consequência da garantia de preços mais baixos em comparação aos que são fabricados no resto do mundo, principalmente os produtos do setor têxtil e de confecções (MARSH, 2007). Diante desse aumento das exportações chinesas, o setor têxtil e de confecções vem sendo pressionado, o que compromete uma significante parcela da indústria de transformação brasileira (DANTAS; GALEANO, 2015).

\section{Referencial Teórico}

O Brasil é desafiado em um panorama de fragmentação crescente das cadeias produtivas e de relações de comércio exterior bilaterais, regionais e multilaterais a se posicionar de maneira vantajosa na participação das cadeias globais de produção. Entretanto, Costa (2014) questiona se a participação do Brasil ou do Mercado Comum do Sul (MERCOSUL) nas redes globais de produção teriam gerado algum benefício de transbordamento nas economias da região e possibilitado sua inserção dinâmica nos mercados internacionais.

Segundo Costa (2014), as especializações dos membros do Mercosul são caracterizadas pelo predomínio das exportações de bens primários e produtos manufaturados abundantes em recursos naturais. Essa especialização dificulta a integração dos países membros do bloco, uma vez que, na hierarquia da fragmentação das cadeias produtivas, estão inseridos entre os mais pobres da cadeia global de produção.

Dentro do escopo da economia internacional, não há questionamentos sobre os benefícios do comércio internacional, mesmo com as distorções causadas pelas barreiras impostas pelos diversos países, o conhecimento sobre como utilizar o padrão de comércio é de extrema importância para estabelecer táticas com o intuito de aumentar o bem-estar econômico. Segundo Hidalgo e da Mata (2008), a especialização em produtos que detenham vantagens comparativas gera oportunidades de ganhos de comércio, o que é vital para a inserção comercial econômica em um mundo crescentemente competitivo e fragmentado.

De acordo com Bonelli (2012), quando o cenário mundial deixou de ser favorável, houve uma forte integração da China e Índia, além de outras economias emergentes, transformando as relações de vantagens comparativas no quadro internacional, com encadeamentos significantes para a indústria de diversos países. Diante dessa perspectiva, a perda da competividade da indústria brasileira converge para a preocupação do futuro da indústria, diante do aumento da concorrência dos 
bens importados e do aumento das exportações de produtos intensivos em recursos naturais na pauta exportadora. Ele então apresenta o argumento de que as economias das Américas e da Europa Ocidental estão sofrendo de um processo precoce de desindustrialização.

Desde 2001, com a entrada da China na Organização Mundial do Comércio (OMC), parte substancial do comércio dos grupos de produtos de médio e alto valor agregado, antes exportados pelos países membros do Mercosul, tem se deslocado para a China, como colocado por Costa (2016). Sugerindo que esses países não tenham aproveitado as oportunidades de uma união aduaneira, o que os teria levado a uma inserção passiva no mercado internacional e na cadeia produtiva global, colocando-se como fornecedores de produtos de baixo valor agregado e montadores dos produtos finais, gerando perda de competividade e redução da capacidade de limitar os efeitos negativos do comércio agressivo chinês sobre suas economias, aumentando incertezas institucionais e restringido as possibilidades de comércio.

\section{Estratégia Empírica}

O corte temporal desta pesquisa compreendeu os períodos de 1997 a 2017. As variáveis utilizadas no estudo foram as exportações, as importações, o Produto Interno Bruto (PIB), a população, a taxa de câmbio e a distância entre países, conforme literatura econômica. Para o estudo do setor têxtil e de confecções serão utilizados os capítulos 50 a 63 do Sistema Harmonizado $(\mathrm{SH})^{4}$. As principais fontes de pesquisa foram a Secretaria de Exportação do Ministério da Indústria, Comércio Exterior e Serviços (SECEX/MDIC/Comex Stat ${ }^{5}$ ), Fundo Monetário Internacional (FMI), Centro de Estudos Prospectivos e Informações Internacionais (CEPII), Banco de Dados de Estatísticas do Comércio Internacional das Nações Unidas (UNCONTRADE), Conferência das Nações Unidas sobre Comércio e Desenvolvimento (UNCTAD) e World Bank.

O modelo gravitacional foi introduzido na economia pela primeira vez por Tinbergen (1962) e posteriormente por Linnemann (1966), gerado da teoria gravitacional da física, é utilizado para explicar os fluxos de comércio bilaterais, indicando que os fluxos de comércio são determinados por forças de atração e por

\footnotetext{
${ }^{4} \mathrm{O}$ Sistema Harmonizado (SH) é uma metodologia internacional de classificação de mercadorias, fundamentado em uma estrutura de códigos e respectivas descrições.

5 O sistema AliceWeb foi desativado e substituído por uma nova plataforma reformulada para simplificar consultas e extrações de dados estatísticos do comércio exterior brasileiro, o Comex Stat. Assim, os dados que foram apresentados com fontes do AliceWeb foram coletados antes da substituição pela nova plataforma.
} 
forças de repulsão (CHENG; WALL, 2005; HELBLE; SHEPHERD; WILSON, 2007; KRUGMAN; OBSTFELD, 2015; AREVALO; ANDRADE; SILVA, 2016).

No final da década de 1970, segundo Santos, Silva e Almeida (2017), o trabalho de Anderson (1979) estabeleceu as bases estruturais para um modelo de gravidade econômica estática dando um embasamento teórico a este tipo de análise, através de uma contextualização teórica balizado nas preferências do tipo Cobb-Douglas e elasticidade de substituição constante (Função CES). Em 2003, Anderson e Van Wincoop (2003) derivaram o modelo que se adapta às mais variadas teorias do comércio internacional, admitindo que os consumidores têm preferência por substitutos, considerando um sistema de demanda para o qual se propõe uma função de elasticidade de substituição constante (CES - Constant Elasticity of Substitution) sujeitas à restrição orçamentária e combinada com condições de equilíbrio de mercado.

A principal característica do modelo proposto por Anderson e Van Wincoop (2003) consiste na adição dos índices de resistência multilateral ao comércio, variáveis não observáveis que são incluídas ao modelo utilizando efeitos fixos. Esse modelo confirma o fato de que modificações nos custos de comércio bilateral tendem a afetar não apenas os fluxos comerciais entre os parceiros comerciais, mas sim, todos os fluxos comerciais por causa dos efeitos dos preços relativos.

Segundo Nascimento e Pregardier Júnior (2013), o modelo em sua formulação básica (equação 1) apresenta uma a equação gravitacional que assume que os fluxos de comércio entre dois países $i$ e $j$ dependendo do: PIB do país importador e exportador, população do país importador e exportador e a distância entre eles. Os aperfeiçoamentos mais comuns relativos ao modelo gravitacional sugerem mudanças em relação às dificuldades do comércio, sejam elas naturais ou artificiais, sendo os naturais ligados ao fator distância, aos custos de transação e transporte e as artificiais, aquelas ligadas principalmente, as políticas de comércio e o relacionamento histórico entre as nações. Nos modelos mais atuais, como em Figueiredo et al (2014) 6 , estão sendo inseridas variáveis de resistência multilateral.

$$
\operatorname{lm} m_{i j}=\beta_{0}+\beta_{1} \ln Y_{i}+\beta_{2} \ln \left(\frac{Y_{i}}{N_{i}}\right)+\beta_{3} \ln Y_{j}+\beta_{4} \ln \left(\frac{Y_{j}}{N_{j}}\right)+\beta_{5} \ln D i s t_{i j}+\varepsilon_{i j}
$$

$m_{i j}$ representa o comércio bilateral entre os países i e j, ou seja, as importações ou exportações nominais ou a soma de ambas; $Y$ é PIB nominal dos países $i$ e $j ; N$ é a

${ }^{6}$ Ressalte-se que este estudo considerou as limitações e críticas ao modelo gravitacional, tal como colocado por Figueiredo et al (2014) e Baldwin e Taglioni (2006), apresentadas nesta seção. 
população dos países i e j; distij é à distância entre os países i e j; $N$ é a população dos países $i$ e $j ; \beta_{0}$ a $\beta_{4}$ são parâmetros que se esperara que tenham sinais positivos e $\beta_{5}$ que apresente sinal negativo; $\varepsilon_{i j}$ é o erro.

Ainda segundo Nascimento e Pregardier Júnior (2013), devido à evolução do comércio global, o modelo tem sofrido diversas alterações como intuito de ampliar seu poder de explicação.

Dada a necessidade de manter a competitividade para ser capaz de atender a demanda crescente no mercado internacional de têxtil e confecções, o presente trabalho analisou os efeitos do fim da proteção comercial internacional do setor $(\text { ATV })^{7}$ sobre o comércio bilateral do Brasil com seus parceiros importadores.

Com relação ao banco de dados, foi considerado o período compreendido entre os anos de 1997 a 2017, englobando-se 187 países que importam produtos do setor têxtil e de confecções do Brasil ${ }^{8}$. A equação estimada é apresentada a seguir:

$$
\begin{aligned}
\operatorname{lnimp}_{i j t}=\beta_{0} & +\beta_{1} \text { lnpib }_{i t}+\beta_{2} \text { lnpib }_{j t}+\beta_{3} \text { lndistcpo }_{i j t}+\beta_{4} \text { pop }_{i j t}+\beta_{5} d f_{i j} \\
& +\beta_{6} \text { excrat }_{i j t}+\beta_{7} \text { datv }_{i t}+\beta_{8} \text { dmerc }_{i t}+\beta_{9} \text { dbric }_{i t}+\varepsilon_{i j t}
\end{aligned}
$$

Para a análise da variável dependente foi escolhida uma variável unilateral para explicar o fluxo de comércio. Para mensurar a variável $i m p_{i j}$ foi utilizada como variável dependente as importações em dólar de todos os países $i$ oriundas do país $j$ (Brasil). Isto devido aos dados de importação dos países mostrarem ser melhores coletados que os dados de exportação (BALDWIN, TAGLIONI, 2006). Segundo Anderson e Wincoop (2003), o modelo gravitacional está sujeito a diversos equívocos empíricos. Baldwin e Taglioni (2006), abordaram os principais erros de especificação presentes na literatura e os classificaram como erros medalhas de ouro, prata e bronze.

A medalha de ouro seria referente ao viés de variável omitida. Segundo Figueiredo et. al (2014), a omissão de variáveis gera uma correlação do erro com os regressores, o que leva a um problema de endogeneidade, superestimando os coeficientes relacionados as variáveis de custo, como a distância entre os países. 0 erro medalha de prata estaria relacionado à escolha da variável dependente.

7 O Acordo sobre Têxteis e Vestuário $(\text { ATV })^{7}$ - 1995 a 2004 - tinha como objetivo eliminar gradualmente o sistema de quotas impostas aos países em desenvolvimento, com o intuito de integrar o comércio de artigos do setor têxtil e de confecção às normas da OMC (COSTA; CONTE; CONTE, 2013).

8 Ver o APÊNDICE A sobre a lista de países e seus respectivos códigos ISO 3166. Que consiste em um conjunto de três normas geográficas para codificar nomes de países e dependências, além das suas principais subdivisões administrativas. 
Em diversos trabalhos o fluxo comercial é representado pela soma ou uma média das exportações do país de origem i para o país de destino j com as importações do país de destino j provindas do país de origem i. Para Baldwin e Taglioni (2006), esse procedimento não possui conexão com a teoria, pois a equaçãogravitacional explicaria apenas o comércio bilateral unidirecional, assim, apenas o fluxo de comércio em exportações ou de importações. Enquanto que o erro medalha de bronze é pertinente a correção dos valores nominais de comércio por um algum índice de preço. Baldwin e Taglioni (2006) argumentam que a inclusão de deflatores geraria viés de correlação espúria, ou seja, gerando correlações sem nenhuma causação.

Para mensurar as variáveis do produto interno bruto ( pib $_{i}$ e pibj ${ }_{j}$ ) foram incluídos o valor nominal em milhões de dólares do Produto Interno Bruto da região importadora $i$ e do país j. Segundo Gräf e Azevedo (2013) o tamanho de uma economia é um fator chave para poder explicar o fluxo de comércio entre dois países, uma vez que o PIB do país exportador reproduz seu potencial competitivo, pelo sua capacidade produtiva e volume de investimentos em novas tecnologias enquanto o PIB do país importador reproduz capacidade financeira que o país possui em contrair e consumir produtos, de modo que quando maior o PIB, maior o volume de comércio bilateral, esperando-se assim um coeficiente positivo para estas variáveis do modelo.

Tal como considerado em por Linnemann (1966), no que diz respeito a variável população $\left(p o p_{i j}\right.$ ) é utilizada como alusão para captar o efeito relacionado ao tamanho do mercado interno de um país. Espera-se um sinal positivo para o coeficiente da variável população, já que esta que baliza o coeficiente entre a produção para o mercado doméstico e para o mercado externo.

Segundo Krugman e Obstfeld (2015), pode-se esperar que maiores distâncias entre as regiões produtoras e os países importadores mostrem um forte efeito negativo no comércio bilateral, isto é, uma vez que quanto maior a distância entre os países, maiores os custos de transportes, o que aumenta o custo de importação de produto, levando a uma tendência natural de comércio com países mais próximos. Para mensurar a variável distância ( distcpo $_{i j}$ ) foi utilizada a distância entre capitais dos países parceiros, ponderada pela participação do PIB mundial dos países importadores, uma vez que, segundo Piani e Kume (2000), existe a necessidade inclusão do conceito de "distância relativa" dos países em relação aos parceiros que têm maior peso econômico mundial, como intuito de diminuir a tendência de 
superestimar ou subestimar os efeitos dos acordos de livre comércio. Mesmo assim, espera-se um sinal negativo do coeficiente para essa variável.

Há uma tendência natural para o comércio bilateral, entre economias fronteiriças, uma vez que existem custos menores de logística. A variável $d f_{i j}$ mensura esse comércio, sendo uma dummy de contiguidade, que assume 0 valor 1 caso ambos os países apresentem contiguidade e 0 caso contrário, sendo esperado do coeficiente um valor positivo para essa variável.

No caso da variável excrat $t_{u j}$, foram utilizadas as taxas de câmbio entre o país $i$ e o país $j$, assim, pode-se inferir um coeficiente negativo, uma vez que maiores taxas de câmbio, ou seja, quanto mais desvalorizada a moeda de uma economia nacional $j$ em relação ao seu parceiro comercial estrangeiro i, menores serão as importações do parceiro $i$ em relação ao país $j$.

Segundo Reis, Azevedo, e Pôrto Júnior (2018), avanços na abertura comercial e integração comercial, no período de 1995 a 2014, beneficiaram mais o setor agrícola e têxtil, do que o setor industrial, sendo resultado dos setores agrícola e têxtil tendo que se adequarem as normas da Organização Mundial do Comércio (OMC). Assim, com relação à dummy datvi, espera-se que a mesma apresente um coeficiente positivo, pois a eliminação dessa barreira ao comércio internacional do setor têxtil e de confecções deve levar a um maior fluxo maior de comércio. Esta dummy binária assume valor 1 , caso o país esteja integrado no comércio de produtos do setor têxtil e de confecção às normas da OMC, ou seja, caso em um cenário de competição internacional sem proteção comercial da OMC; ou 0, caso contrário.

Dentro da teoria do comércio internacional, a participação em um bloco econômico é eficaz em diminuir as barreiras comerciais formais e estimula significativamente o comércio internacional entre seus parceiros (KRUGMAN; OBSTFELD, 2015). Partindo do pressuposto anterior, as variáveis dmerc $c_{i}$ e dbric que capturam os efeitos dos blocos econômicos Mercosul e BRICS, tendem a apresentar um sinal do coeficiente positivo, uma vez que, espera-se uma intensidade maior de comércio entre os países pertencentes a esses blocos. Dessa forma, para a variável $d m e r c_{i}$ será atribuído o valor 1 caso a região importadora $i$ for membro do Mercosul ou 0 caso contrário. Semelhantemente para a variável 
$d b r i c_{i}$ será atribuído o valor 1 caso a região importadora i for membro do BRICS $^{9}$ ou 0 caso contrário.

As variáveis utilizadas no estudo, principais referenciais teóricos, sinal esperado e respectivas fontes de pesquisa, referentes ao modelo econométrico, estão resumidas no Quadro 1.

Considerando que os dados referentes ao modelo teórico correspondem a um fenômeno macroeconômico que sofre interferências das peculiaridades entre diversos indivíduos, que são monitorados em mais de um período de tempo, o mais adequado para este trabalho corresponde a um modelo com dados em painel, mais especificamente, modelos lineares de regressão para dados em painel. De modo que possuem muito mais informações, maior variação nos dados, maior número de graus de liberdade, menor multicolinearidade entre as suas variáveis e maior eficiência na estimação dos parâmetros (MARQUES, 2000).

Mais especificamente, será estimado um modelo linear de regressão para dados em painel curto ${ }^{10}$, uma vez que os dados da base, variam entre indivíduos e ao longo do tempo, e tem por variável dependente, uma variável métrica ou qualitativa. Trata-se de um painel curto, pois o número de indivíduos é maior que o período de tempo analisado.

O objetivo da regressão em dados de painel é justamente estudar o desempenho de determinada variável dependente, que represente o fenômeno de interesse, com base no comportamento de variáveis explicativas, cujas mudanças podem acontecer tanto em relação aos indivíduos em um, como em diversos períodos de tempo.

Foram testados três tipos de estimações de modelos de regressão de dados em painel: POLS ou Pooled Ordinary Least Squares, estimação por Efeitos Fixos e estimação por Efeitos Aleatórios.

A estimação por POLS considera a base se dados como uma grande crosssection e, por meio do OLS (Ordinary Least Square), estima os parâmetros do modelo. Segundo Gujarati e Porter (2011), o principal problema desse modelo é que ele não faz distinção entre indivíduos, não levando em consideração a heterogeneidade. $\mathrm{E}$ os termos de erro devem estar correlacionados ao longo do

\footnotetext{
9 O acrônimo "BRICS" faz referência as economias emergentes do Brasil, Rússia, Índia, China e África do Sul.

${ }^{10}$ Um painel curto é caracterizado por ter um número de indivíduos em uma cross-section, $\mathrm{N}$, maior que o número de períodos de tempo T (GUJARATI; PORTER,2011; CAMERON; TRIVEDI, 2009).
} 
tempo para um dado indivíduo, sendo necessário corrigir os erros padrão para ser feito algum teste de hipóteses.

O modelo de regressão de efeitos fixos considera a existência de efeitos individuais que representam as heterogeneidades entre os indivíduos e consideram suas diferenças invariantes no tempo (FÁVERO, 2015). Para a estimação dos parâmetros desse modelo são eliminados os efeitos individuais por meio da elaboração de uma transformação within aplicada pela diferenciação das médias, com a consequência de que dados de uma variável que não variam ao longo do tempo não serão estimados (CAMERON; TRIVEDI, 2009, GUJARATI; PORTER, 2011).

O modelo por efeitos aleatórios é estimado pelo método e Mínimos Quadrados Generalizados (MQG), considera a variação entre indivíduos aleatória e não correlacionada com as variáveis explicativas (FÁVERO, 2015).

Após realizadas as estimações, foram verificados como os parâmetros estimados e os seus respectivos erros variaram de modelo a modelo. Foi observado se existia ou não heterogeneidade no modelo. Se a heterogeneidade fosse observada no modelo, não haveria efeitos observáveis e o método mais adequado para a estimação do modelo seria o método POLS, oferecendo estimativas consistentes e eficientes; caso contrário, deveriam ser usadas metodologias que podem modelar a heterogeneidade, como os métodos de efeitos fixos ou aleatórios. Se a heterogeneidade não observável fosse correlacionada com as variáveis explicativas o modelo deveria ser analisado pelo modelo de efeitos fixos, caso contrário, pelo modelo de efeitos aleatórios (SCHUCH; UHR; UHR, 2016).

Com o intuito de comparar os estimadores gerados pelos modelos POLS e por efeitos aleatórios, foi utilizado o teste LM (Lagrange Multiplier) de Breush-Pagan. Esse teste possibilita observar se a variância entre indivíduos é 0 , sendo a hipótese nula $\mathrm{H}_{0}$ : modelo POLS, ou se existe diferenças estatisticamente diferentes entre os indivíduos nos dados, sendo $\mathrm{H}_{1}$ : efeitos aleatórios, a determinado nível de significância. O teste de $\mathrm{F}$ de Chow apresenta em seus resultados qual melhor estimador, entre POLS e efeitos fixos. Sua hipótese $\mathrm{H}_{0}$ é que todos os efeitos entre indivíduos é zero.

Para decidir sobre a escolha entre os modelos estimados por efeitos fixos ou por efeitos aleatórios, foi usado o teste de Hausman, que averigua se os efeitos individuais são aleatórios, existindo assim consistência entre os parâmetros estimados por efeitos fixos e aleatórios ( $\mathrm{H}_{0}$ : efeitos aleatórios), ou se os efeitos 
individuais não são aleatórios e não existe consistência entre os dois parâmetros (H1: efeitos fixos), a um dado nível de significância.

Dado que o teste de Hausman parte do pressuposto que os termos de erro obtidos após estimação por efeitos aleatórios sejam aleatórios e distribuídos igualmente, isso não ocorre na estimação com erros-padrão robustos (Cameron e Trivedi, 2009). Assim o teste de Shaffer e Stillman (2010), utiliza a estatística de $\chi^{2}$ de Sargan-Hansen, que considera os erros-padrão robustos.

Segundo Gujarati e Porter (2011), apesar das vantagens dos modelos de regressão para dados em painel, existem problemas de estimação, uma vez que, como se tem a união de cross-sections e séries temporais, algumas vezes resultam em problemas de heterocedasticidade e autocorrelação. Devido a influência temporal não ser muito significativa em painéis curtos, não será identificado a correlação serial de primeira ordem nos termos de erros (FÁVERO, 2013).

Para detectar a presença de heterocedasticidade utilizou-se o teste de Wald, sendo a hipótese nula de variância constante (homocedasticidade). A solução desse problema foi dada através da estimação da existência de erros-padrão robustos.

\section{Resultados e Discussão}

$\mathrm{Na}$ Tabela 2, encontram-se os resultados do modelo de regressão para dados em painel, a partir do modelo econométrico (equação 2) estimado: o modelo pooled ordinary least squares (pols), o modelo de efeitos aleatórios e o modelo de efeitos fixos, todos com erros robustos para correção da heterocedasticidade, além de apresentar os resultados de todos os testes realizados ${ }^{11}$.

Os testes realizados indicaram pela seleção do modelo de efeitos fixos como mais eficiente. Porém algumas hipóteses importantes do modelo não podem ser estimadas pelos efeitos fixos, como os efeitos da fronteira entre os países e a participação nos blocos econômicos, devido a constância dessas variáveis no tempo. Os resultados do modelo revelam que as variáveis independentes explicam, no geral, $49 \%$ da variável dependente. Entre as unidades ( $R$-sq between), o ajuste do modelo é de $61 \%$ e dentro das unidades ( $R$-sq within) o ajuste é de $10 \%$. De tal modo que o PIB dos países importadores, o PIB do Brasil, a população dos

\footnotetext{
${ }^{11}$ As variáveis foram trabalhadas em log para simples suavização do modelo, trazendo melhores resultados estatísticos.
} 
países importadores, a distância entre capitais ponderada pelo PIB, a taxa de câmbio entre o Brasil, os parceiros comerciais e a dummy de integração comercial explicam cerca de 49 \% das importações dos parceiros comerciais para o Brasil, com relação ao setor têxtil e de confecções, no período entre 1997 a 2017.

Segundo Castilho (2002), é observado mundialmente que modelos com um maior nível de desagregação apresentam valores de coeficientes de estimação inferiores, de modo que variáveis como o PIB e população, que são medidas agregadas, têm sua capacidade explicativa limitada quando se realizam análises desagregadas.

Analisando o modelo gravitacional, verifica-se que o coeficiente para o Produto Interno Bruto dos parceiros comerciais do Brasil é de um coeficiente positivo de 1,403 ao nível de significância de 1\%, mantendo assim uma estimativa próxima ao esperado, que é de uma unidade, segundo Shepherd (2013).

Para o coeficiente estimado do Produto Interno Bruto do Brasil, a estimativa por efeitos fixos revela um resultado contrário ao esperado positivo e com a intensidade mais baixa que dos parceiros comerciais apresentando um coeficiente negativo de 0,971 ao nível de significância de 1\%.

O comportamento da variável distância entre os países apresentou sinal negativo, como esperado, esperando-se assim que quanto maior a distância entre os países, mesmo quando ponderado pela participação do PIB dos parceiros comerciais do Brasil, menor é o comércio entre eles. Mas, não apresentou significância estatística a 5\%. Este resultado é coerente com a prática comercial, que tem colocado em xeque o argumento do modelo gravitacional de relacionar maior comércio a distâncias menores, haja vista o caso Brasil-China.

Com relação ao coeficiente da variável população dos países importadores, obteve-se o sinal esperado, mas também não foi estatisticamente significativo, indicando que o efeito relacionado ao tamanho do mercado interno de um país, quanto maiores os mercados internos, maiores os fluxos comerciais entre os países, não é significante para explicar os determinantes das importações do setor têxtil e de confecções para o Brasil.

O coeficiente da taxa de câmbio revelou um sinal negativo igual ao esperado e significância a 1\%, indicando que quanto mais desvalorizada a moeda do Brasil em relação a um parceiro comercial, menores serão as importações desse parceiro comercial, com relação a produtos do setor têxtil e de confecções. Esse resultado é alicerçado por Rodrik (2007), que afirma que a taxa de câmbio é uma variável 
estratégica para o crescimento, e que existe uma relação direta entre taxas de câmbio mais desvalorizadas e crescimento de longo prazo, sendo uma análise apenas válida para países em desenvolvimento. Resultado semelhante é encontrado por Arevalo, Andrade e Silva (2016), que evidenciaram que taxas de câmbio desvalorizadas foram significantes para induzir aumentos nas exportações internacionais de café do Brasil e Peru.

Para capturar o impacto da liberalização do comércio internacional do setor têxtil e de confecções foi utilizado a dummy de integração comercial que assumiu valor 1 para os anos posteriores à eliminação total do sistema de cotas do mercado dos produtos têxteis e de confecções (2005 a 2017). Embora o setor tenha ficado desprotegido e vulnerável às oscilações do mercado internacional, com a liberalização já se esperava um aumento dos fluxos de comércio, efeito captado pela dummy. Os resultados da estimação apresentaram um coeficiente com sinal positivo, igual ao esperado, e estatisticamente significativo a 5\%.

Resultado similar foi obtido por Santos, Silva e Almeida (2017) analisando um produto diretamente afetado pelo fim do acordo ATV (Acordo sobre Têxteis e Vestuário), em que mesmo com uma maior vulnerabilidade devido às oscilações no comércio de algodão com a liberalização, chegou-se a uma taxa de crescimento maior do comércio após a eliminação das cotas de importação, um aumento em média de $153 \%$ no comércio internacional e $230 \%$ nos países menos desenvolvidos e em desenvolvimento, quando comparado ao período anterior ao fim do acordo ATV, corroborando os resultados positivos da abertura comercial e da maior integração econômica, sobre o fluxo do comércio desse produto.

Nassar (2007) notou que antes do fim do ATV as empresas de algodão e similares já haviam começado novos investimentos com o intuito de estimular a demanda. A China, mesmo depois de alguns anos fora do mercado começou a importar grande volume de algodão a partir de 2002. Além de dar um enfoque ao aumento na produção de algodão no Brasil e em países da África Subsaariana, sendo decisiva a liberalização do comércio para o avanço desse mercado.

\section{Considerações Finais}

Esta pesquisa teve como objetivo analisar os efeitos do fim da proteção comercial internacional do setor $(\mathrm{ATV})^{12}$ sobre o comércio bilateral do Brasil com

12 O Acordo sobre Têxteis e Vestuário (ATV) ${ }^{12}$ - 1995 a 2004 - tinha como objetivo eliminar gradualmente o sistema de quotas impostas aos países em desenvolvimento, com o intuito de 
seus parceiros importadores. Indicando através do modelo gravitacional, que mesmo com a falta de competitividade do Brasil no setor têxtil e de confecções, com a liberalização comercial do setor foi registrada uma taxa de crescimento maior do comércio após a eliminação das cotas de importação, em comparação quando o Acordo sobre Têxteis e Vestuário (ATV) estava em vigor, mostrando os efeitos positivos da abertura comercial e da maior integração econômica. Revelando que a integração econômica internacional com relação ao setor têxtil e de confecções a partir de 2005 impactou positivamente sobre o fluxo de comércio, sendo este um resultado significante diante de um cenário internacional atual de aumento de protecionismo comercial internacional.

Apesar desses resultados, convém ressaltar que o principal parceiro comercial do Brasil, a China, que se apresenta no cenário internacional com expressivos superávits comerciais e alardeados ganhos de competitividade, liderando não somente os BRICS, mas se colocando como entrave à soberania norte-americana no comércio internacional, tem tido suas políticas comerciais questionadas por diversos países junto à $\mathrm{ONU}$, em virtude de práticas de dumping, restrições diretas e indiretas às exportações dos parceiros comerciais, políticas cambiais com forçosa desvalorização da moeda para favorecer o comércio externo, baixa remuneração da mão de obra local, levando à competitividade espúria com outras economias.

Portanto, tomar conhecimento das vantagens de um ambiente de comércio amplamente competitivo é vital para se analisar tendências e avaliar políticas para melhor inserção do setor no comércio internacional. Nesse sentido, compreender como e de onde vêm os ganhos de comércio dos parceiros comerciais também é importante elemento para se manter no ranking de países com alguma fatia deste mercado.

\section{Referências}

ANDERSON, J. E. A theoretical foundation for the gravity equation. The American Economic Review, v. 69, n. 1, p. 106-116, 1979.

ANDERSON, J. E.; VAN WINCOOP, E. Gravity with gravitas: a solution to the border puzzle. American Economic Review, v.93, n.1. 2003. 
ARAUJO, R.A. et al. Análise de viabilidade estratégica de novos entrantes no setor de confecção de roupas no Brasil. Sistema \& Gestão, v.14, n.1, p. 50-63, 2019. DOI $10.20985 / 1980-5160$.

AREVALO, J. L. S.; ANDRADE, A. M. F.; SILVA, G. A. B. Uma Nota Sobre Modelos Gravitacionais Aplicados à Exportação de Café de Brasil, Colômbia e Peru. Revista Brasileira de Economia, v. 70, n. 3, p. 271-280, 2016.

BALDWIN, R.; TAGLIONI, D. Gravity for dummies and dummies for gravity equations. National Bureau of Economic Research, 2006.

BEZERRA, F. D. Análise retrospectiva e prospectiva do setor têxtil no Brasil e no Nordeste. Informe Técnico do ETENE. Informe Macroeconomia, Indústria e Serviços, Fortaleza, Ano VIII, n. 2, 2014.

BONELLI, ; PINHEIRO, A. Competitividade e Desempenho Industrial: Além do Câmbio. FGV/IBRE (Texto para Discussão), 2012.

CAMERON, A. C.; TRIVEDI, P. K. Microeconometrics using Stata. Revised Edition. College Station: Stata press, 2009.

CASTILHO, M.R. O acesso das exportações do Mercosul ao mercado europeu.

Pesquisa e Planejamento Econômico, vol. 32, n. 1, p. 149-198, 2002).

COSTA, A. B.; CONTE, N. C.; CONTE, V. C. A China na cadeia têxtil - vestuário: impactos após a abertura do comércio brasileiro ao mercado mundial e do final dos Acordos Multifibras (AMV) e Têxtil Vestuário (ATV). Revista Teoria e Evidência Econômica, 2013.

COSTA, L. V., et al. Competitividade e Padrão de Especialização do Fluxo Industrial de Comércio Exterior do Paraná, 1996 a 2008. Revista de Economia, vol.38, nํ3, p.7-29, 2012.

COSTA, K. G. V. D. Fragmentação internacional da produção e sofisticação das exportações: uma análise a partir dos fluxos de comércio do Mercosul entre 1994 e 2012. In 42 Encontro Nacional de Economia - ANPEC, Anais..., Florianópolis, 2016.

DANTAS, M. P.; GALEANO, R. Impacto da relação Brasil-China no setor de confecções. Revista de Administração do Sul do Pará (REASP)-FESAR 2 (2015).

FÁVERO, L. P. Análise de dados: modelos de regressão com Excel®, Stata® e SPSS®. Elsevier Brasil, 2016.

FEISTEL, P. R.; HIDALGO, A. B. A Competitividade das regiões brasileiras no intercâmbio comercial com a China, 2012.

FIGUEIREDO, E. et al. Uma análise para o efeito-fronteira no Brasil. Revista Brasileira de Economia, v. 68, n. 4, p. 481-496, 2014.

GRÄF, C. O.; AZEVEDO, A. F. Z. Comércio bilateral entre os países membros do mercosul: uma visão do bloco através do modelo gravitacional. Economia Aplicada, v. 17, n. 1, p. 135-158, 2013. 
GORINI, P. F. Panorama do setor têxtil no Brasil e no Mundo: reestruturação e perspectivas. BNDES Setorial, Rio de Janeiro, 2000.

GUJARATI, D. N.; PORTER, D. C. Econometria Básica-5. 2011.

HIDALGO, Á. B.; MATA, F. P. G. D. Inserção das regiões brasileiras no comércio internacional: os casos da Região Nordeste e do Estado de Pernambuco. Ensaios FEE, Porto Alegre,v.26, n. 2, p. 79-108, 2008.

KRUGMAN, P. R.; OBSTFELD M. Economia Internacional. 10. Pearson, 2015.

KUME, H. As Tarifas aduaneiras no Brasil são excessivamente elevadas? Radar: tecnologia, produção e comércio exterior, $n^{\circ} 56,2018$.

LEAMER, E. E; STERN, R. M. Quantitative international economics. Chicago: Allyn and Bacon, 1970

MARQUES, L. et al. Modelos dinâmicos com dados em painel: revisão de literatura. Centro de estudos Macroeconómicos e Previsão, faculdade de Economia do Porto, 2000.

MARSH. P. Brazil venture takes textile fight to China. The Financial Times. Business News: n.1, p17, 2007.

MAZZUCHETTI, R. N.; SHIKIDA, P. F. O comércio internacional do açúcar sob a perspectiva do modelo gravitacional. Revista de Ciências Agrárias, v. 40, n. 2, p. 210-220, 2017.

MENDES JÚNIOR, B. O. Setor têxtil. Caderno Setorial - ETENE, 2017.

MIRANDA, P. Política tarifária de importações do Brasil em debate. Radar: tecnologia, produção e comércio exterior, $n^{\circ} 56,2018$.

MIRANDA, P.; CASTILHO, M. Tarifa aduaneira como instrumento de política de desenvolvimento produtivo: contribuições para o debate recente no Brasil. Radar: tecnologia, produção e comércio exterior, $n^{\circ} 56,2018$.

NASCIMENTO, F.; JÚNIOR, D. P. A evolução do modelo gravitacional na economia. Revista Saber Humano, Recanto Maestro, n. 3, p. 163-175, 2013.

NASSAR, A. M. Trade Liberalization in Cotton and Sugar. Agricultural Trade Liberalization and the Least Developed Countries, v. 19, p. 83, 2007.

OGASAVARA, M. H.; MASIERO, G. Oferta do trabalho na China: o sistema Hukou e o paradoxo da escassez, Revista Economia \& Gestão, v. 13, n. 31, p. 115-137, 2013.

PIANI, G.; KUME, H. Fluxos bilaterais de comércio e blocos regionais: uma aplicação do modelo gravitacional. 2000. Texto para Discussão IPEA (TD0749).

PRATES, R. C.; PEREIRA, H. P. Análise dos fatores determinantes do comércio internacional brasileiro: uma análise do modelo gravitacional. Reflexões

Econômicas, v. 1, n. 1, p. 105-129, 2015. 
REIS, M.; AZEVEDO, A. F. Z.; PÔRTO JÚNIOR, S. S. Impactos da OMC sobre o comércio de produtos primários, têxteis e industriais. ANPEC- Associação Nacional dos Centros de Pós-Graduação em Economia. 2018.

REIS, J. D. Análise do crescimento das exportações brasileiras de carne bovina entre 1990 e 2002: uma aplicação do modelo constant market share. Ceres, vol.55, nำ3, 2015.

RODRIK, D. The real exchange rate and economic growth: Theory and evidence. [Kennedy School of Government manuscript]. In Center for global development. (2007).

SANTOS, M. O.; SILVA, O. M.; ALMEIDA, F. M. Uma análise das restrições comerciais no mercado internacional de algodão. Revista de Estudos Sociais, v. 19, n. 38, p. 67-85, 2017.

SCHUCH, R. C.; UHR, D. A. P.; UHR, J. G. Z. Comércio internacional brasileiro: evidências da crise econômica de 2008. Perspectiva Econômica, v. 12, n. 2, p. 116, 2016.

SILVA, T. J. J. D. Desempenho exportador da manda e da uva brasileira no comércio internacional: uma análise entre o período de 2003 a. Dissertação - UFPE. Caruaru p.75, 2015.

SOUZA, M. J. P.; BURNQUIST, H. L. Impactos da facilitação de comércio: evidências do modelo gravitacional. Revista de Economia e Sociologia Rural, v. 49, n. 4, p. 909-940, 2011.

STAIGER, R.W.; SYKES, A.O. 'Currency Manipulation' and World Trade. Program in Law and Economics. Stanford Law School. Working Paper, n.363, jun 2008.

SUBRAMANIAN, A.; KESSLER, M. The hyperglobalization of trade and its future. 2013.

WOOLDRIDGE, J. M. Introdução à econometria: uma abordagem moderna. São Paulo: Cengage Learning, 2016.

WU, M. The China, Inc. Challenge to Global Trade Governance, Harvard International Law Journal, n.57, p. 261, 2016.

YOTOV, Y. et al. An Advanced Guide to Trade Policy Analysis: The Structural Gravity Model. World Trade Organization, Geneva, 2016. 


\section{NOTAS DE AUTOR}

\section{CONTRIBUIÇÃO DE AUTORIA}

Thiago Fellipe Lima Silva Pereira - Concepção, coleta e análise de dados, elaboração e revisão do manuscrito. Monaliza de Oliveira Ferreira - Concepção, participação ativa na discussão dos resultados, revisão e aprovação da versão final do trabalho.

\section{FINANCIAMENTO}

Não se aplica. O estudante tem bolsa CAPES, mas no momento da elaboração do artigo ainda não era bolsista.

\section{CONSENTIMENTO DE USO DE IMAGEM}

Não se aplica

\section{APROVAÇÃO DE COMITÊ DE ÉTICA EM PESQUISA \\ Não se aplica}

\section{CONFLITO DE INTERESSES}

Não se aplica

\section{LICENÇA DE USO}

Este artigo está licenciado sob a Licença Creative Commons CC-BY. Com essa licença você pode compartilhar, adaptar, criar para qualquer fim, desde que atribua a autoria da obra.

\section{HISTÓRICO}

Recebido em: 03-01-2020

Aprovado em: 10-09-2020

\section{Tabela 01 - Comércio de mercadorias do setor têxtil e de confecções (US\$} Bilhões)

\begin{tabular}{cccccccccc}
\hline & \multicolumn{3}{c}{ Brasil/China } & \multicolumn{3}{c}{ China/Mundo } & \multicolumn{3}{c}{ Brasil/Mundo } \\
& Exp & Imp & SC & Exp & Imp & SC & Exp & Imp & SC \\
\hline 1997 & 0,00 & 0,18 & $-0,18$ & 43,22 & 17,21 & 26,01 & 1,27 & 2,35 & $-1,08$ \\
2001 & 0,00 & 0,09 & $-0,09$ & 49,83 & 16,26 & 33,57 & 1,31 & 1,23 & 0,08 \\
2005 & 0,11 & 0,36 & $-0,25$ & 107,66 & 23,44 & 84,22 & 2,22 & 1,52 & 0,70 \\
2009 & 0,08 & 1,37 & $-1,29$ & 161,33 & 21,78 & 139,55 & 1,90 & 3,48 & $-1,58$ \\
2013 & 0,21 & 3,52 & $-3,30$ & 273,96 & 40,42 & 233,54 & 2,37 & 6,80 & $-4,43$ \\
2016 & 0,11 & 2,12 & $-2,01$ & 253,22 & 28,37 & 224,85 & 2,21 & 4,21 & $-2,00$ \\
2017 & - & - & - & - & - & - & 2,37 & 5,09 & $-2,72$ \\
\hline \multicolumn{4}{c}{ Fonte: Elaboração própria, dados do UN Comtrade (2018). }
\end{tabular}

Quadro 1 - Variáveis utilizadas no modelo econométrico (1997-2017)

\begin{tabular}{|c|c|c|c|c|}
\hline Variável & Descrição & $\begin{array}{l}\text { Sinal } \\
\text { Esperado }\end{array}$ & $\begin{array}{l}\text { Referencial teórico e } \\
\text { empírico }\end{array}$ & Fonte \\
\hline$I m p_{i j}$ & $\begin{array}{l}\text { Fluxo de comércio, } \\
\text { medido em termos } \\
\text { dos valores das } \\
\text { importações. }\end{array}$ & & $\begin{array}{l}\text { Figueiredo et al (2014); } \\
\text { Baldwin e Taglioni } \\
\text { (2006); Souza e } \\
\text { Burnquist (2011). }\end{array}$ & UNCONTRADE \\
\hline$p i b_{i}$ e $p i b_{j}$ & $\begin{array}{l}\text { Produto Interno } \\
\text { Bruto (PIB) da } \\
\text { região importadora e } \\
\text { do País exportador, } \\
\text { respectivamente. }\end{array}$ & $(+)$ & $\begin{array}{llr}\text { Schuch, } & \text { Uhr e } & \text { Uhr } \\
\text { (2016); Souza } & \text { e } \\
\text { Burnquist } & \text { (2011); Gräf e } \\
\text { Azevedo } & \text { (2013); } \\
\text { Mazzuchetti } & \text { e } & \text { Shikida } \\
\text { (2017) } & & \end{array}$ & World Bank \\
\hline
\end{tabular}




\begin{tabular}{|c|c|c|c|c|}
\hline Distp $_{i j}$ & $\begin{array}{l}\text { Distância entre as } \\
\text { capitais dos países, } \\
\text { ponderada pelo PIB. }\end{array}$ & $(-)$ & Gräf e Azevedo (2013) & $\begin{array}{c}\text { CEPII } \\
\text { World Bank }\end{array}$ \\
\hline$P_{P o p_{i}}$ & $\begin{array}{l}\text { População do País } \\
\text { importador. }\end{array}$ & $(+)$ & $\begin{array}{l}\text { Silva } \\
\text { Mazzuchetti e } \\
\text { (2017) }\end{array}$ & World Bank \\
\hline$\overline{D f_{i}}$ & $\begin{array}{l}\text { Dummy existência } \\
\text { de contiguidade }\end{array}$ & $(+)$ & $\begin{array}{l}\text { Prates e Pereira (2015); } \\
\text { Gräf e Azevedo (2013); } \\
\text { Schuch, Uhr e Uhr } \\
\text { (2016) }\end{array}$ & CEPII \\
\hline Excratij $_{i j}$ & $\begin{array}{l}\text { Taxa de câmbio } \\
\text { entre os países } i \text { e } j\end{array}$ & $(-)$ & $\begin{array}{l}\text { Arevalo, Andrade } \mathrm{e} \\
\text { Silva (2016) }\end{array}$ & UNCTAD \\
\hline $\operatorname{Datv}_{i}$ & $\begin{array}{l}\text { Dummy proteção } \\
\text { comercial } \\
\text { internacional }\end{array}$ & $(+)$ & $\begin{array}{l}\text { Santos, Silva e Almeida } \\
\text { (2017) }\end{array}$ & - \\
\hline Dmerc $_{i}$ & $\begin{array}{l}\text { Dummy participação } \\
\text { no Mercosul }\end{array}$ & $(+)$ & $\begin{array}{l}\text { Prates e Pereira (2015); } \\
\text { Mazzuchetti e Shikida } \\
\text { (2017); Schuch, Uhr e } \\
\text { Uhr (2016) }\end{array}$ & - \\
\hline Dbrici & $\begin{array}{l}\text { Dummy participação } \\
\text { BRICS }\end{array}$ & $(+)$ & $\begin{array}{l}\text { Mazzuchetti e Shikida } \\
(2017)\end{array}$ & - \\
\hline
\end{tabular}

Tabela 2 - Resultados das estimações do modelo proposto

\begin{tabular}{|c|c|c|c|}
\hline Variável & Pols & $E F$ & $E A$ \\
\hline \multirow{2}{*}{ Inpib } & $2.763^{\star \star \star}$ & $1.403^{* * *}$ & $2.046^{\star * \star}$ \\
\hline & 0.382 & 0.416 & 0.259 \\
\hline \multirow[t]{2}{*}{ Inpibg } & $-1.481^{* \star *}$ & $-0.971^{\text {*** }}$ & $-1.19^{\star \star *}$ \\
\hline & 0.205 & 0.199 & 0.171 \\
\hline \multirow{2}{*}{ Indist } & $-1.423^{* * *}$ & -0.071 & $-0.679^{* * *}$ \\
\hline & 0.351 & 0.481 & 0.247 \\
\hline \multirow[t]{2}{*}{$d f r$} & $2.76^{\star * *}$ & (omitido) & $3.687^{\star \star \star}$ \\
\hline & 0.67 & & 0.552 \\
\hline \multirow[t]{2}{*}{ Inpop } & -0.039 & 0.324 & -0.133 \\
\hline & 0.109 & 0.647 & 0.103 \\
\hline \multirow[t]{2}{*}{ excrat } & $-0.19^{\star \star \star}$ & $-0.275^{\star \star \star}$ & $-0.272^{\star \star \star}$ \\
\hline & 0.075 & 0.049 & 0.049 \\
\hline \multirow[t]{2}{*}{ datv } & -0.125 & $0.356^{\star \star}$ & 0.207 \\
\hline & 0.185 & 0.139 & 0.132 \\
\hline \multirow[t]{2}{*}{ dmerc } & -0.346 & (omitido) & $-0.036^{\star *}$ \\
\hline & 1.061 & & 1.044 \\
\hline \multirow[t]{2}{*}{ dbrics } & -1.321 & (omitido) & -0.855 \\
\hline & 0.834 & & 0.721 \\
\hline \multirow[t]{2}{*}{ _cons } & $7.423^{\star \star \star}$ & 6.441 & $10.721^{* \star *}$ \\
\hline & 2.487 & 9.265 & 2.391 \\
\hline $\mathrm{N}$ & 2692 & 2692 & 2692 \\
\hline r2 & 0.625 & 0.098 & \\
\hline
\end{tabular}




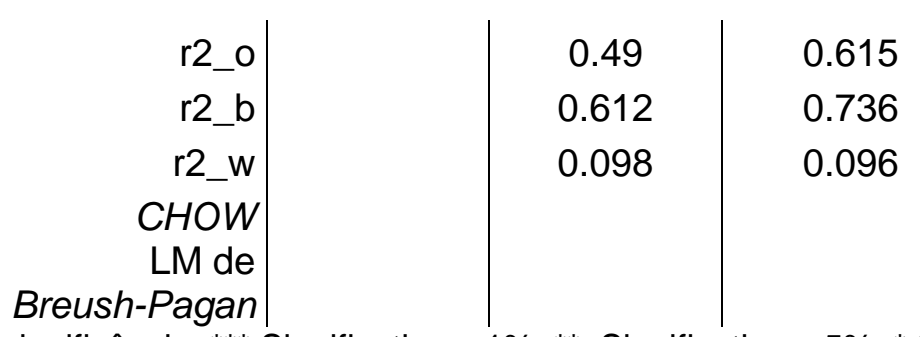

Nota: Níveis de significância: ${ }^{* *}$ Significativo a $1 \%$. **; Significativo a 5\%; * Significativo a $10 \%$.

Fonte: Elaboração própria, dados da pesquisa. Software STATA.

\section{ANEXO}

TABELA 1A - Países que importam produtos do setor têxtil e de confecções do Brasil

\begin{tabular}{|c|c|c|c|c|c|}
\hline País & Código & País & Código & País & Código \\
\hline Albania & ALB & FS Micronesia & FSM & Palau & PLW \\
\hline Algeria & DZA & Gabon & GAB & Panama & PAN \\
\hline Andorra & AND & Gambia & GMB & Papua New Guinea & PNG \\
\hline Angola & AGO & Georgia & GEO & Paraguay & PRY \\
\hline Anguilla & AIA & Germany & DEU & Peru & PER \\
\hline $\begin{array}{l}\text { Antigua and } \\
\text { Barbuda }\end{array}$ & ATG & Ghana & $\mathrm{GHA}$ & Philippines & PHL \\
\hline Argentina & ARG & Greece & GRC & Poland & POL \\
\hline Armenia & ARM & Greenland & GRL & Portugal & PRT \\
\hline Aruba & ABW & Grenada & GRD & Qatar & QAT \\
\hline Australia & AUS & Guatemala & GTM & Rep. of Korea & KOR \\
\hline Austria & AUT & Guinea & GIN & Rep. of Moldova & MDA \\
\hline Azerbaijan & AZE & Guyana & GUY & Romania & ROU \\
\hline Bahamas & $\mathrm{BHS}$ & Honduras & HND & Russian Federation & RUS \\
\hline Bahrain & $\mathrm{BHR}$ & Hungary & HUN & Rwanda & RWA \\
\hline Bangladesh & BGD & Iceland & ISL & Saint Kitts and Nevis & KNA \\
\hline Barbados & BRB & India & IND & Saint Lucia & LCA \\
\hline Belarus & BLR & Indonesia & IDN & $\begin{array}{l}\text { Saint Vincent and the } \\
\text { Grenadines }\end{array}$ & VCT \\
\hline Belgium & BEL & Iran & IRN & Samoa & WSM \\
\hline $\begin{array}{l}\text { Belgium- } \\
\text { Luxembourg }\end{array}$ & BEL & Ireland & IRL & Sao Tome and Principe & STP \\
\hline Belize & $B L Z$ & Israel & ISR & Saudi Arabia & SAU \\
\hline Benin & BEN & Italy & ITA & Senegal & SEN \\
\hline Bermuda & BMU & Jamaica & JAM & Serbia & SRB \\
\hline Bhutan & BTN & Japan & JPN & Serbia and Montenegro & SCG \\
\hline Bolivia & $\mathrm{BOL}$ & Jordan & JOR & Seychelles & SYC \\
\hline $\begin{array}{l}\text { Bosnia } \\
\text { Herzegovina }\end{array}$ & $\mathrm{BIH}$ & Kazakhstan & $\mathrm{KAZ}$ & Sierra Leone & SLE \\
\hline Botswana & BWA & Kenya & KEN & Singapore & SGP \\
\hline Brazil & BRA & Kuwait & KWT & Slovakia & SVK \\
\hline $\begin{array}{l}\text { Brunei } \\
\text { Darussalam }\end{array}$ & BRN & Kyrgyzstan & KGZ & Slovenia & SVN \\
\hline Bulgaria & BGR & Lao & LAO & So. African & ZAF \\
\hline Burkina Faso & BFA & Latvia & LVA & Solomon Isds & SLB \\
\hline
\end{tabular}




\begin{tabular}{|c|c|c|c|c|c|}
\hline Burundi & BDI & Lebanon & LBN & South Africa & ZAF \\
\hline Ivory Coast & CIV & Libya & LBY & Spain & $\mathrm{ESP}$ \\
\hline Cabo Verde & CPV & Lithuania & LTU & Sri Lanka & LKA \\
\hline Cambodia & KHM & Luxembourg & LUX & State of Palestine & PSE \\
\hline Cameroon & CMR & Madagascar & MDG & Sudan & SDN \\
\hline Canada & CAN & Malawi & MWI & Suriname & SUR \\
\hline Chile & $\mathrm{CHL}$ & Malaysia & MYS & Sweden & SWE \\
\hline China & $\mathrm{CHN}$ & Maldives & MDV & Switzerland & $\mathrm{CHE}$ \\
\hline Hong Kong & HKG & Mali & MLI & Syria & SYR \\
\hline Macao & MAC & Malta & $\mathrm{MLT}$ & Macedonia & MKD \\
\hline Colombia & $\mathrm{COL}$ & Mauritania & MRT & Thailand & THA \\
\hline Comoros & COM & Mauritius & MUS & Timor-Leste & TLS \\
\hline Congo & COG & Mayotte & MYT & Togo & TGO \\
\hline Costa Rica & $\mathrm{CRI}$ & Mexico & MEX & Trinidad and Tobago & TTO \\
\hline Croatia & HRV & Mongolia & MNG & Tunisia & TUN \\
\hline Cuba & CUB & Montenegro & MNE & Turkey & TUR \\
\hline Cyprus & CYP & Montserrat & MSR & Tuvalu & TUV \\
\hline Czechia & CZE & Morocco & MAR & Uganda & UGA \\
\hline Denmark & DNK & Mozambique & MOZ & Ukraine & UKR \\
\hline Dominica & DMA & Myanmar & MMR & United Arab Emirates & ARE \\
\hline Dominican Rep. & DOM & Namibia & NAM & United Kingdom & GBR \\
\hline Ecuador & ECU & Nepal & NPL & Tanzania & TZA \\
\hline Egypt & EGY & Neth. Antilles & ANT & Uruguay & URY \\
\hline El Salvador & SLV & Netherlands & NLD & USA & USA \\
\hline Eritrea & ERI & New Caledonia & $\mathrm{NCL}$ & Vanuatu & VUT \\
\hline Estonia & EST & New Zealand & NZL & Venezuela & VEN \\
\hline Ethiopia & ETH & Nicaragua & NIC & Viet Nam & VNM \\
\hline Faeroe Isds & $\mathrm{FRO}$ & Niger & NER & Wallis and Futuna Isds & WLF \\
\hline Fiji & FJI & Nigeria & NGA & Yemen & YEM \\
\hline Finland & FIN & Norway & NOR & Zambia & ZMB \\
\hline Fmr Sudan & SDN & Oman & OMN & Zimbabwe & ZWE \\
\hline France & FRA & Other Asia, nes & 0 & & \\
\hline $\begin{array}{l}\text { French } \\
\text { Polynesia }\end{array}$ & PYF & Pakistan & PAK & & \\
\hline
\end{tabular}

Fonte: Elaboração própria, dados do International Organization for Standardization (ISO). 